\title{
Relationships between respiratory diseases and quartz-rich dust in Idaho, U.S.A.
}

\author{
MichaEL R. NORTON ${ }^{1}$ AND MiCKey E. GUNTER ${ }^{2, *}$ \\ ${ }^{1}$ Interface Computer School, 9921 North Nevada, Spokane, Washington 99218-1126, U.S.A. \\ ${ }^{2}$ Department of Geology and Geological Engineering, University of Idaho, Moscow, Idaho 83844-3022, U.S.A.
}

\begin{abstract}
Quartz-one of the most abundant minerals in the Earth's crust—has been deemed a human carcinogen by the International Agency for Research on Cancer (IARC), with the main threat to humans being lung cancer through inhalation of dust particles. Currently, the United States Environmental Protection Agency (EPA) has required communities to monitor PM10 (particulate matter less than 10 micrometers in diameter) levels, with the concern that higher levels of PM10 have been linked to increased respiratory disease rates. This hypothesis can be tested by an analysis of mortality data for groups that have received high lifelong exposures to quartz-rich PM10 (e.g., farmers). Idaho is a very dusty state with a large agricultural community and can serve as a model to test this hypothesis.

A database was constructed of PM10 levels statewide and of all the deaths attributed to respiratory diseases in Idaho from 1969 to 1994. For the Moscow, Idaho, PM samples, quartz composed approximately $10 \%$ of the PM10, with the remainder being $30 \%$ feldspar and $60 \%$ Mount St. Helens volcanic ash. The PM2.5 samples contained no detectable mineral matter. Statewide, the quartz component for the PM10 samples ranged from 7 to $16 \%$. Analysis of the database indicates that Idaho residents, in general, have below-average lung cancer rates when compared to the U.S. population and that Idaho farmers are at no greater risk of dying from lung cancer than non-farmers. These conclusions are based upon age- and smoking-adjusted standard mortality ratios (SMRs). No correlations or trends between PM10 levels and respiratory diseases could be found in the general population. Data for chronic obstructive pulmonary diseases (COPDs) are more difficult to interpret because of fewer deaths and the inability to compensate for the effect of smoking in the induction of these diseases; however, it appears that Idaho has a higher rate of COPDs when compared to the U.S. populations and that farmers have a higher rate of COPDs than non-farmers.
\end{abstract}

\section{INTRODUCTION}

This project was initiated in response to two regulatory developments: (1) an International Agency for Research on Cancer (IARC) ruling to upgrade quartz from a Group 2A to a Group 1 human carcinogen (IARC 1997) and (2) an EPA requirement that communities monitor PM10 (EPA 1986) and a possible modification of EPA guidelines to include PM2.5 (EPA 1996). To determine whether inhalation of large amounts of quartz-rich dust in rural settings increases the risk of lung cancer, we developed a project to: (1) characterize the amount and mineralogical compositions of PM10 in Idaho, especially with respect to quartz content, (2) build an epidemiological database of respiratory diseases and occupations in Idaho, concentrating on lung cancer rates and farmers, and (3) determine if any relationships exist between PM10 amounts, compositions, and respiratory diseases.

Most people associate silicosis with inhalation of quartz. Silicosis is a debilitating disease of the lung caused by inhalation of large amounts of quartz over a long period of time, as

*E-mail:mgunter@uidaho.edu may occur in an occupational setting. Silicosis and other types of pneumoconiosis (e.g., asbestosis, black lung) fiberlize portions of the lung, resulting in decreased $\mathrm{O}_{2}-\mathrm{CO}_{2}$ exchange and, in some cases, death by heart failure. Silicosis is a rare disease and is not a form of cancer. In the U.S., only 135 people died of silicosis in 1988, whereas 133,284 died of lung cancer (Feinleid 1991). In Idaho, an average of one person per year dies of silicosis (Norton 1996). Silicosis historically has been a disease associated with mining operations. Attention in America was drawn to this disease in the early 1900s regarding the granite workers of the northeast (Davis et al. 1983; Ross et al. 1993; Russel 1941). For reviews of the human lung function and silicosis, see U.S. EPA (1995), Goldsmith (1994), Ross et al. (1993), and Skinner et al. (1988).

Because of the association between silicosis and quartz dust, quartz became a suspected human carcinogen. Consequently, over the past 20 years many epidemiological studies have focused on the carcinogencity of quartz (e.g., Frazier and Sundin 1986; Hnizdo and Sluis-Cremer 1991) in conjunction with animal studies (e.g., Dagel et al. 1986; Spietoff et al. 1992; Wagner et al. 1980) and in vitro studies (e.g., Saffiotti et al. 1993). IARC (1997), Goldsmith (1994), and Ross et al. (1993) provide good overviews of this research. IARC has five classi- 
fications for carcinogenic materials: Group 1 is carcinogenic to humans; Group $2 \mathrm{~A}$ is probably carcinogenic to humans; Group $2 \mathrm{~B}$ is possibly carcinogenic to humans; Group 3 is not classifiable as to its carcinogenicity to humans; and Group 4 is probably not carcinogenic to humans. Based upon animal inhalation studies, the IARC listed quartz as a Group 2A human carcinogen (IARC 1987a; 1987b). This classification triggered the U.S. Occupational Safety and Health Administration (OSHA) to establish regulations for quartz-containing materials under the Hazard Communication Standard Act of 1983, which mandated that products containing more than $0.1 \%$ quartz (by weight or volume) be labeled as a possible human carcinogen (Ross et al. 1993). Recently, the IARC (1997) reclassified quartz and cristobalite to Group 1 status, based on "sufficient evidence" for carcinogenicity in humans and animals. IARC's decisions are made by a 19-member panel of health science professionals; no mineralogists or petrologists are included in the panel. It is difficult to predict what ramifications this ruling will have on the mining and farming industries in the U.S.

In the regulatory arena, the term "crystalline silica" refers to any of the crystalline silica polymorphs and differentiates these from the amorphous phases of silica. Because quartz is by far the most abundant of the silica polymorphs on the Earth's surface, and one of the most abundant minerals in the Earth's crust (Klein 1993), it is the main silica polymorph of concern. Currently, amorphous silica has a Group 3 listing (IARC 1997); however, there has been (EPA 1995; Checkoway et al. 1993) and continues to be a concern, warranted or not, about inhalation of amorphous silica. Heaney et al. (1994) provides an excellent discussion of the silica minerals and amorphous forms of silica.

It has been known since Biblical times (Goldsmith 1994) and documented since the 1500s (Agricola 1556; Paracelsus 1567) that exposure to high dust levels in mining operations leads to lung disorders. It was Paracelsus (1567) who made one of the most far-reaching conclusions in the field of toxicology that "the dose makes the poison." The EPA (1986) set "dose levels" for PM10. The $10 \mu \mathrm{m}$ size was chosen because particulates of this diameter can penetrate deep into the human lung. Under EPA guidelines, communities must monitor PM10 levels and develop plans to reduce PM10 if necessary. Current guidelines state that PM10 levels cannot exceed $150 \mu \mathrm{g} / \mathrm{m}^{3}$ of air in a 24 hour period or a maximum of $50 \mu \mathrm{g} / \mathrm{m}^{3}$ in a one year period. EPA (1996) also proposed to add PM2.5 guidelines, given new evidence that this size is more dangerous than PM10. They propose PM2.5 guidelines to be in the range of $20-65 \mu \mathrm{g} / \mathrm{m}^{3}$ for a 24 hour period and $12.5-20 \mu \mathrm{g} / \mathrm{m}^{3}$ for a one year period.

The PM regulations are based upon studies focused in metropolitan areas, for example the "Harvard Six-Cities Study" (Dockery et al. 1993). Many of these studies involved the correlation of daily PM levels to hospital emergency room visits for respiratory diseases. Schwartz $(1994,1995,1996)$ published a series of papers on this subject. Interestingly, no studies have examined the relationship between PM levels and disease in rural areas. Rural studies are important gauges of disease induction by minerals, because PM10 produced from farming has a high inorganic component, while PM2.5 is a combustion product composed mostly of hydrocarbons and is typical of urban settings (EPA 1996).

\section{AIR SAMPLING AND PARTICULATE MATTER}

Dust was obtained from air using various sampling devices. High volume samplers pulled large volumes of air $\left(1 \mathrm{~m}^{3}\right.$ of air per minute) through 8 inch $\times 12$ inch glass-fiber filters over short periods, usually 1 hour. The glass-fiber filters consist of fused silica, which complicates the determination of the major elemental chemistry of PM10, because the filters must be dissolved to determine the elemental composition of the PM10. The Si content of the filter prevents determination of $\mathrm{Si}$ in the PM10, and Si is the most abundant metal in PM10. (The air sampling community has incorrectly inferred that quartz content cannot be measured by these filters (e.g., by X-ray diffraction methods), which are sometimes referred to as "quartz-fiber filters.") Filters were weighed before and after known volumes of air were drawn through them, and PM10 values in micrograms of dust per cubic meter of air $\left(\mu \mathrm{g} / \mathrm{m}^{3}\right)$ were calculated by the methods discussed in EPA (1986).

Lower volume samplers, called virtual impactors, collect samples over longer periods at lower flow rates $\left(1 \mathrm{~m}^{3}\right.$ of air per hour for days or weeks). Some of these samplers, termed dichotomous samplers, divide the particulate matter into two distinct size fractions (e.g., 0-2.5 $\mu \mathrm{m}$ and 2.5-10 $\mu \mathrm{m}$ ) and deposit the samples onto $37 \mathrm{~mm}$ circular filters. The disadvantage of this type of sampler is that it collects very low weights, 5-10 $\mathrm{mg}$, even after 1 to 2 week collection periods. An advantage is that the PM10 can be removed from the filter material, usually composed of PVC, and different analytical methods can be performed on dust samples. [Norton (1996) and NIOSH 7500 give details of filter dissolution and sample preparation.] For this project, two Anderson Series 1500 virtual impactors refitted with PM10 heads were used.

Data that found Idaho to be the most dusty state in comparison with the other 49 states were taken from the AIRS Executive program, version 3.0 (AIRS Executive Computer Software 1996). This database contains 9487 observations from 1990 to 1996, from which a weighted PM10 value for each state was calculated. PM10 data from 1986 to 1996 were also provided by the Idaho Department of Environmental Quality (DEQ), which monitors PM10 levels pursuant to EPA regulations. The months of June, July, August, and September were used for analysis, as these are considered the dry summer months. The average PM10 value, along with a standard deviation, were calculated for each month. Finally, a PM10 average for each location was determined. Unfortunately, PM10 data were only available for 14 of 44 counties (Table 1). Within these 14 counties, there were 32 sampling sites and 136 observations for each of the 4 months used in the study. See Appendix in B Norton (1996) for the raw data.

To supplement the statewide PM10 data provided by the DEQ, we collected PM10 samples to develop methods to quantify the quartz content of the PM10, both locally (i.e., near Moscow, Idaho) and statewide. Our two samplers were placed on the west side of the University of Idaho's campus in Moscow, Idaho, which is located on the western side of Latah County (Fig. 1). The predominant wind direction is from the west, blowing into Idaho from the central Washington desert. Samplers were placed at the same location so we could collect duplicate samples for more detailed analysis and also so we could send 
TABLE 1. Summary of deaths from 1969 to 1994 (raw data provided by the Idaho Department of Vital Statistics), SMRs, PM10 data from 1986 to 1994 (raw data provided by the ldaho DEQ), smoking rates from 1983 to 1989 (Idaho Department of Vital Statistics), and precipitation from 1965 to 1994 in Idaho (raw data provided by Idaho State Climate services)

\begin{tabular}{|c|c|c|c|c|c|c|c|c|c|}
\hline $\begin{array}{l}\text { Ref. } \\
\text { No. }\end{array}$ & $\begin{array}{l}\text { County } \\
\text { In Idaho }\end{array}$ & $\begin{array}{l}\text { PM10 } \\
\mu \mathrm{g} / \mathrm{m}^{3}\end{array}$ & $\begin{array}{l}\text { total } \\
\text { deaths }\end{array}$ & $\begin{array}{c}162 \\
\text { SMR }^{*}\end{array}$ & $\begin{array}{c}162 \\
\text { adjusted }\end{array}$ & $\begin{array}{c}\text { COPDs } \\
\text { SMR }\end{array}$ & $\begin{array}{l}\text { COPDs } \\
\text { adjusted }\end{array}$ & $\begin{array}{c}\text { Smoking } \\
(\%)\end{array}$ & $\begin{array}{l}\text { precp. } \\
\text { (inches) }\end{array}$ \\
\hline 1. & Ada† & $34(12)$ & 30129 & 129(3) & $137(3)$ & $85(4)$ & 104(5) & $21(1)$ & 13 \\
\hline 2. & Adams & - & 671 & $145(22)$ & $125(19)$ & $64(24)$ & $61(23)$ & $21(-)$ & 34 \\
\hline 3. & Bannock $\dagger$ & $37(13)$ & 10867 & $76(4)$ & $100(5)$ & $128(9)$ & $171(11)$ & $20(2)$ & 14 \\
\hline 4. & Bear Lake & - & 1573 & $43(8)$ & $39(7)$ & $89(19)$ & 79(19) & $18(-)$ & 20 \\
\hline 5. & Benewah & - & 1897 & $128(13)$ & 132(13) & $84(16)$ & $85(17)$ & $18(5)$ & 21 \\
\hline 6. & Bingham & - & 6178 & $62(5)$ & $87(5)$ & $89(9)$ & $116(12)$ & $15(2)$ & 15 \\
\hline 7. & Blaine & - & 1383 & $89(12)$ & $158(22)$ & $88(20)$ & $128(29)$ & $13(3)$ & 23 \\
\hline 8. & Boise & - & 513 & 122(23) & $130(25)$ & $143(41)$ & $152(44)$ & $21(-)$ & 33 \\
\hline 9. & Bonnert & $29(9)$ & 5297 & $129(8)$ & $110(6)$ & $106(11)$ & 104(11) & $24(3)$ & 44 \\
\hline 10. & Bonneville & $30(12)$ & 9968 & $65(4)$ & $94(6)$ & $84(7)$ & $122(10)$ & $18(2)$ & 15 \\
\hline 11. & Boundary & - & 1558 & $110(13)$ & 108(13) & $78(18)$ & $79(18)$ & 19(6) & 22 \\
\hline 12. & Butte & - & 669 & $86(17)$ & $84(17)$ & 118(33) & $122(34)$ & $18(-)$ & 12 \\
\hline 13. & Camas & - & 169 & $96(36)$ & $97(37)$ & $180(81)$ & 207(93) & $20(-)$ & 22 \\
\hline 14. & Canyon & $46(18)$ & 17983 & $101(4)$ & $96(4)$ & $88(6)$ & $79(5)$ & $19(2)$ & 11 \\
\hline 15. & Caribou & $37(16)$ & 1233 & $58(10)$ & $81(15)$ & $133(26)$ & $183(35)$ & $19(-)$ & 22 \\
\hline 16. & Cassia & - & 3643 & $63(6)$ & $77(8)$ & $125(15)$ & $140(16)$ & $15(4)$ & 17 \\
\hline 17. & Clark & - & 154 & $90(37)$ & $112(46)$ & $198(88)$ & $207(93)$ & $16(-)$ & 21 \\
\hline 18. & Clearwater & $34(12)$ & 2007 & $129(12)$ & $113(11)$ & 124(19) & $134(21)$ & $28(6)$ & 51 \\
\hline 19. & Custer & - & 788 & $73(15)$ & $73(15)$ & $162(35)$ & $152(33)$ & $16(-)$ & 19 \\
\hline 20. & Elmore & - & 2776 & $127(10)$ & $181(15)$ & $112(16)$ & $213(30)$ & $30(3)$ & 26 \\
\hline 21. & Franklin & - & 1940 & $27(6)$ & $30(6)$ & $66(14)$ & $55(12)$ & $12(4)$ & 35 \\
\hline 22. & Fremont & - & 2000 & $51(8)$ & $55(8)$ & $97(17)$ & $110(19)$ & $21(4)$ & 28 \\
\hline 23. & Gem & - & 3042 & $108(9)$ & $62(5)$ & $94(14)$ & $73(11)$ & $32(5)$ & 16 \\
\hline 24. & Gooding & - & 2989 & 104(9) & $72(6)$ & $86(13)$ & $61(9)$ & $22(4)$ & 9 \\
\hline 25. & Idaho & - & 3311 & $102(8)$ & $92(8)$ & $112(14)$ & $97(13)$ & $19(3)$ & 33 \\
\hline 26. & Jefferson & - & 2511 & $55(7)$ & $75(10)$ & $114(17)$ & $146(21)$ & $15(4)$ & 9 \\
\hline 27. & Jerome & - & 3028 & 103(9) & $89(8)$ & $85(13)$ & $79(12)$ & $25(5)$ & 10 \\
\hline 28. & Kootenai & $34(25)$ & 12860 & $140(5)$ & $123(4)$ & $94(7)$ & $91(7)$ & $24(2)$ & 26 \\
\hline 29. & Latah & $46(-)$ & 4814 & $79(6)$ & $111(9)$ & $78(10)$ & $91(12)$ & $12(3)$ & 32 \\
\hline 30. & Lemhi & $41(20)$ & 1736 & $121(13)$ & $99(10)$ & $147(23)$ & 128(20) & $24(6)$ & 19 \\
\hline 31. & Lewis & $27(6)$ & 1006 & $96(15)$ & $79(12)$ & $115(26)$ & $91(21)$ & $20(-)$ & 23 \\
\hline 32. & Lincoln & - & 803 & $75(15)$ & $66(13)$ & $68(23)$ & $61(23)$ & $19(-)$ & 10 \\
\hline 33. & Madison & - & 2179 & $24(5)$ & $66(14)$ & $45(11)$ & $85(21)$ & $4(1)$ & 14 \\
\hline 34. & Minidoka & - & 3387 & $92(8)$ & $114(10)$ & $104(14)$ & $128(17)$ & $17(3)$ & 9 \\
\hline 35. & Nez Perce & $36(15)$ & 8329 & $117(6)$ & $89(4)$ & $124(10)$ & $104(8)$ & $25(3)$ & 12 \\
\hline 36. & Oneida & - & 987 & $37(10)$ & $32(8)$ & $111(26)$ & $73(17)$ & $17(-)$ & 22 \\
\hline 37. & Owyhee & - & 1669 & 111(12) & $92(10)$ & $106(20)$ & $97(18)$ & $25(8)$ & 16 \\
\hline 38. & Payette & - & 4046 & $106(8)$ & $68(5)$ & $128(14)$ & $97(11)$ & $28(4)$ & - \\
\hline 39. & Powert & - & 1179 & $76(12)$ & $102(16)$ & $129(26)$ & 164(33) & $19(-)$ & 17 \\
\hline 40. & Shoshone† & $23(9)$ & 4654 & $149(9)$ & $108(6)$ & $94(11)$ & $97(12)$ & $32(3)$ & 50 \\
\hline 41. & Teton & - & 612 & $42(13)$ & $46(14)$ & $149(39)$ & 164(43) & $16(-)$ & 17 \\
\hline 42. & Twin Falls & $35(12)$ & 12052 & $94(4)$ & $80(4)$ & $127(8)$ & $104(7)$ & $21(2)$ & 14 \\
\hline 43. & Valley & - & 1116 & $145(17)$ & $206(25)$ & $82(21)$ & $97(25)$ & $13(4)$ & 34 \\
\hline \multirow[t]{2}{*}{44.} & Washington & - & 2,567 & 110(10) & $75(7)$ & $102(16)$ & $61(9)$ & 19(4) & 23 \\
\hline & Idaho statewide & 32 & 182273 & $84(1)$ & $93(1)$ & 141(1) & $155(3)$ & 20 & - \\
\hline
\end{tabular}

Notes: All values are monthly averages.

* SMRs for Idaho counties calculated based on Idaho death rates. SMRs for Idaho statewide calculated based on U.S. death rates.

† Counties that do not meet EPA guidelines for PM10 (i.e., non-attainment areas).

‡"-"= not calculated or not available.

samples to other analytical laboratories. Table 2 summarizes our data collected for the Moscow region. Sampling times varied from one week in the dustier summer months to one month in the winter months. For the complete set of PM10 and PM2.5 data see Norton (1996).

\section{Mineralogy OF PARTICUlate MATTER}

Scientists have investigated the elemental composition of PM10 (EPA 1995; 1996), but less is known about the phases that constitute it. Mineral matter and filters from high volume air samplers can be digested for chemical analysis exclusive of $\mathrm{Si}$. But the chemistry alone, especially without $\mathrm{Si}$, does not reveal the major mineral phases found in PM10. One of the main goals of this project was to determine the amount of quartz and other minerals in the dust. Of the various analytical methods we tested, powder X-ray diffraction proved to be the best for analyzing our small sample quantities.

\section{Powder X-ray diffraction}

Quantitative analysis for quartz. The National Institute for Occupational Safety and Health (NIOSH) developed the method NMAM 7500 for X-ray diffraction analysis of PM10 deposited on silver membrane filters. We used this method with slight modifications. Three to five standards were created with the following weights (in micrograms) of PM10 quartz: 250, 375, 500, 625, 750, 1000, 1500, 2500, 5000, and 7500 (see Norton 1996, Appendix D; NIOSH 1994). Each standard was scanned by a Siemens D5000 $\theta-\theta$ X-ray diffractometer using $\mathrm{Cu} K \alpha$ radiation at $40 \mathrm{kV}$ and $30 \mathrm{~mA}$ equipped with a solidstate detector. Each sample was run with a step size of $2 \theta=$ $0.020^{\circ}$ and a count time of $40 \mathrm{~s}$ per step. The (100) peak of quartz $\left(2 \theta=20.35-21.35^{\circ}\right)$ and the $(111)$ peak of silver $(2 \theta=$ $\left.37.5-38.5^{\circ}\right)$ were used for calibration. The (100) quartz peak was chosen because the dominant (101) peak overlaps with a muscovite peak. After background subtraction, integrated ar- 


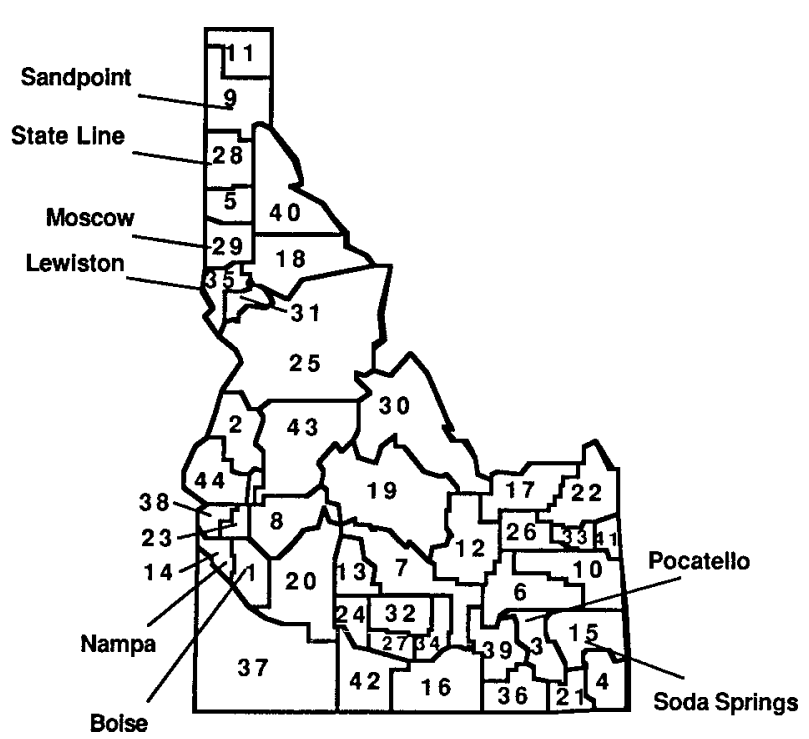

FigURE 1. State map of Idaho with counties numbered in alphabetical order corresponding to those numbers given in Table 1. Also, eight specific locations are shown. Our dichotomous sampler for PM10 and PM2.5 was located at the University of Idaho in Moscow. The seven other locations where we determined the quartz content from high volume air samplers deposited on glass-fiber filters obtained from Idaho DEQ are also shown.

eas for the (100) quartz and (111) Ag peaks for the series of standards produced a calibration curve. A test of the calibration equation yielded $371 \mu \mathrm{g}$ for a $375 \mu \mathrm{g}$ sample and $636 \mu \mathrm{g}$ for a $625 \mu \mathrm{g}$ sample (i.e., errors of $1-2 \%$ by weight).

PM samples were collected on $37 \mathrm{~mm}$ circular PVC filters, redeposited onto $25 \mathrm{~mm}$ silver membrane filters, and scanned using the same parameters as the standards. Quantities of quartz were determined using the calibration equation. Because of the quantity of non-quartz minerals on each filter, an absorption correction must be applied to the calculations (Norton 1996; NIOSH 1994). Analysis by an independent private laboratory (DataChem, Salt Lake City, Utah) was in excellent agreement with our results. Our X-ray diffraction analysis of the PM2.5 samples yielded no detectable mineral matter. We also sent PM2.5 samples to the same private laboratory and they also found no mineral matter. A summary is given in Table 2. For complete results, see Norton (1996).

Feldspar quantification. Based upon X-ray diffraction, feldspar was a major component of our PM10. To quantify the feldspar content, we used a modification of the reference intensity ratio (RIR) method as outlined in Snyder and Bish (1989). Rather than referencing peaks to corundum, though, we selected quartz as the internal standard because it is present in all the samples, and the amount of quartz was determined independently. Thus, we replaced the $I / I_{\mathrm{c}}$ value given in Snyder and Bish (1989) with $I / I_{\mathrm{q}}$ values obtained from 1:1 mixtures of quartz and feldspar. In these standards, preferred orientation, inhomogeneity of mixing, and variable crystallinity were minimized by reducing the samples to less than $10 \mu \mathrm{m}$ and using "back-fill" sample holders.

Measurement of feldspar content (Table 2) was limited by
TABLE 2. PM10 data collected for the Moscow area (PM values in $\mu \mathrm{g} / \mathrm{m}^{3}$ )

\begin{tabular}{lcrrrc}
\hline \hline Date & PM2.5 & PM2.5-10 & PM10 & $\begin{array}{c}\text { quartz } \\
(\%)\end{array}$ & $\begin{array}{c}\text { feldspar } \\
(\%)\end{array}$ \\
\hline July 1995 & 6 & 21 & 27 & $-{ }^{*}$ & - \\
August 1995 & 4 & 22 & 26 & - & - \\
September 1995 & 6 & 28 & 34 & 8.6 & 28 \\
October 1995 & 6 & 15 & 21 & 11.0 & 23 \\
November 1995 & 3 & 6 & 10 & 8.8 & 33 \\
December 1995 & 1 & 4 & 5 & 12.6 & - \\
January 1996 & 1 & 6 & 7 & - & - \\
February 1996 & 4 & 8 & 12 & - & - \\
March 1996 & 1 & 7 & 8 & 2.6 & - \\
April 1996 & 2 & 13 & 15 & - & - \\
July 1996 & 1 & 10 & 11 & 11.8 & - \\
* “-"= not calculated or not available & & & \\
\hline
\end{tabular}

several factors: (1) diffracted intensities for feldspars were typically weaker than the diagnostic (100) and (101) peaks for quartz, and (2) small amounts of PM10 decreased the accuracy of quartz quantification, thereby increasing the error in feldspar analysis. We extended the RIR method to muscovite with only limited success, because there was very little muscovite in the samples. Muscovite concentrations averaged approximately $3 \mathrm{wt} \%$.

\section{Noncrystalline materials on filters and point counting}

The mineral content of the PM10 samples typically constituted about $40 \mathrm{wt} \%$ of the totals (Table 2). Based on XRD, no other major crystalline phases could account for the remaining $60 \mathrm{wt} \%$. (Neither were hydrocarbons detected on the summer filters in the DataChem analysis.) The most likely possibility was that the remaining material was amorphous, possibly volcanic ash.

By point counting with an Hitachi S-2300 SEM-EDS equipped with a solid-state detector, each particle was identified as either quartz, feldspar, or volcanic glass based upon its chemistry and/or morphology. Of 112 particles examined (from the September 1995 PM10 sample, Table 2), 11 were quartz, 32 were feldspar, and 69 were volcanic glass. Thus, quartz was calculated to be $10 \%$, feldspar $29 \%$, and volcanic ash $61 \%$, which compares favorably to the quartz content of $8.6 \%$ and feldspar content of $28 \%$ obtained by X-ray diffraction (Table 2 ).

Point counting was also attempted using a transmission electron microscope but proved unsuccessful because we found that many of the particles contained both amorphous and crystalline areas, and most of the particles were too thick for good diffraction results, leaving only the edges, perhaps weathered, for analysis.

\section{Quantitative analysis for quartz from high volume air samplers}

The Idaho DEQ loaned us the 8 inch $\times 12$ inch glass-fiber filters from their statewide analysis. To our knowledge, no previous analysis of the quantity of quartz on glass-fiber filters had been attempted. The DEQ sent three filters from each of their locations (see Fig. 1) for the months of June through September. All filters had PM10 values of $50 \mu \mathrm{g} / \mathrm{m}^{3}$ or less. Seven of the locations, which were distributed throughout the state, were selected for X-ray diffraction analysis. The filters with the lowest and highest amounts of material were analyzed for each loca- 
tion. We performed X-ray scans over only the (101) peak of quartz. We changed to the more intense (101) peak from the (100) peak because of high background associated with the glass-fiber filters. (These filters are composed of amorphous silica, and as stated above, sometimes are referred to as "quartz-fiber" filters.) Long count times, $300 \mathrm{~s}$ for every $0.020^{\circ} 2 \theta$ step, were used to resolve the (101) peak from the high background.

Because the DEQ collected high volume samples on 8 inch $\times 12$ inch glass-fiber filters in Moscow concurrent with our own sample collection on PVC filter media in a low volume sampler, we developed a means of converting X-ray diffraction data from the 8 inch $\times 12$ inch filters into quantitative quartz contents. First, we measured the intensity of the (101) quartz peak from the DEQ filter based in Moscow and assumed it corresponded to $10 \%$ quartz based upon values shown in Table 2 and the results from point counting. We could then calculate the remaining quartz percentages on filters throughout the state. The calculations were performed as follows. The (101) peak area for quartz was measured for the Moscow-based filter and found to be 1.35 , and the PM10 value was known as $45 \mu \mathrm{g} / \mathrm{m}^{3}$. Thus, by dividing the (101) peak area by the PM10 amount, we arrived at a factor of 0.0375 . By assuming a $10 \%$ quartz content on the filter, we derived the following equation to calculate the percent quartz on the filters:

$$
\text { quartz }(\%)=\frac{[(101) \text { peak area }] / \text { PM10 }}{0.0375} \bullet 10 \%
$$

All quartz values in Table 3 were calculated in this manner. Quartz ranged from 6 to $16 \%$ for the state of Idaho. This range agrees with other studies (EPA 1995). Table 3 contains seven locations: Sandpoint, State Line, and Lewiston are in Bonner, Kootenai, and Nez Perce counties, respectively, which are located in northern Idaho. Boise and Nampa are in Ada and Canyon counties, respectively, which represent our southwestern Idaho locations. Finally, Soda Springs and Pocatello are in Caribou and Bannock counties, respectively, and represent our southeastern Idaho locations.

Figure 2 shows powder $\mathrm{X}$-ray diffraction scans of the quartz (101) peaks from the DEQ filters from each region in the state. We included our own Ag membrane filter from Moscow for comparison. Note that the peak heights of our Moscow sample are not directly comparable because the count time was $15 \mathrm{~s}$, whereas

TABLE 3. State-wide quartz values from glass-fiber filters

\begin{tabular}{lrrrrr}
\hline Sample & Date & $\begin{array}{l}(100) \\
\text { location }\end{array}$ & $\mu$ rea dust & PM10 & quartz(\%) \\
\hline Boise & $(7 / 1)$ & 1.4 & 71.6 & 50 & 7 \\
Boise & $(7 / 7)$ & 1.8 & 63.7 & 44 & 11 \\
Lewiston & $(7 / 1)$ & 1.4 & 79.3 & 49 & 8 \\
Lewiston & $(7 / 19)$ & 1.4 & 76.3 & 48 & 8 \\
Nampa & $(6 / 25)$ & 1.0 & 68.4 & 45 & 6 \\
Nampa & $(7 / 13)$ & 1.5 & 75.7 & 49 & 8 \\
Pocatello & $(9 / 1)$ & 1.8 & 65.7 & 48 & 10 \\
Pocatello & $(9 / 13)$ & 2.3 & 63.8 & 46 & 13 \\
Sandpoint & $(7 / 1)$ & 1.9 & 50.6 & 33 & 15 \\
Sandpoint & $(8 / 24)$ & 2.0 & 71.8 & 46 & 12 \\
Soda Springs & $(7 / 1)$ & 1.7 & 48.0 & 37 & 12 \\
Soda Springs & $(9 / 20)$ & 1.8 & 56.5 & 43 & 11 \\
State Line & $(7 / 1)$ & 2.7 & 68.2 & 45 & 16 \\
State Line & $(7 / 7)$ & 2.8 & 74.8 & 48 & 16 \\
standard & & 1.4 & 65.3 & 45 & 10 \\
\hline Notes:Samples & & & & \\
\hline
\end{tabular}

Notes: Samples provided by the Idaho DEQ and collected in 1994. the glass-fiber filters had a count time of $300 \mathrm{~s}$. However, the quartz peak is easily resolved from the background on a scan that was only $15 \mathrm{~s}$ on the silver filter, while the glass-fiber filters took a much longer scan time. Also, the background on the glassfiber filters is much higher, as discussed previously.

\section{EPIDEMIOLOGICAL DATA}

\section{Respiratory diseases}

To determine whether naturally occurring ambient dust levels that are rich in crystalline silica contribute to an increase in respiratory diseases, we performed an epidemiological study on data obtained from the Idaho Department of Vital Statistics and the Vital Statistics of the U.S. (Feinleib 1991). The database was also constructed to determine whether deaths from respiratory diseases in Idaho were above the U.S. average and if farmers, who work in very dusty environments, have higher than expected respiratory disease rates.

\section{Classification}

Lung cancer and other diseases are classified according to a numerical classification system of the International Committee for Diseases (ICD) (World Health Organization 1977). This system has been changed several times, most recently in 1979 . Our data covers two classification periods, ICD8 (prior to 1979) and ICD9 (1979 to present). The newer classification further divides certain diseases into their own numerical categories.

The diseases of interest here included malignant neoplasms of the respiratory system (160-165), specifically lung cancer (162), and the chronic obstructive pulmonary diseases, specifically bronchitis (491), emphysema (492), and asthma (493), which are collectively designated here as chronic obstructive pulmonary diseases, or COPDs (491-493). These diseases were selected because they occur quite frequently and are associated with high dust concentrations and smoking. Other diseases such as silicosis, asbestosis, and mesothelioma were examined but occurred too rarely for a meaningful statistical analysis. For example, there is usually only one death per year in Idaho from silicosis.

Lung cancer is the most common of these respiratory diseases, followed by emphysema, asthma, and bronchitis. The number of deaths from asthma and bronchitis is very similar and usually ranges from 15 to 25 deaths per year in Idaho. In

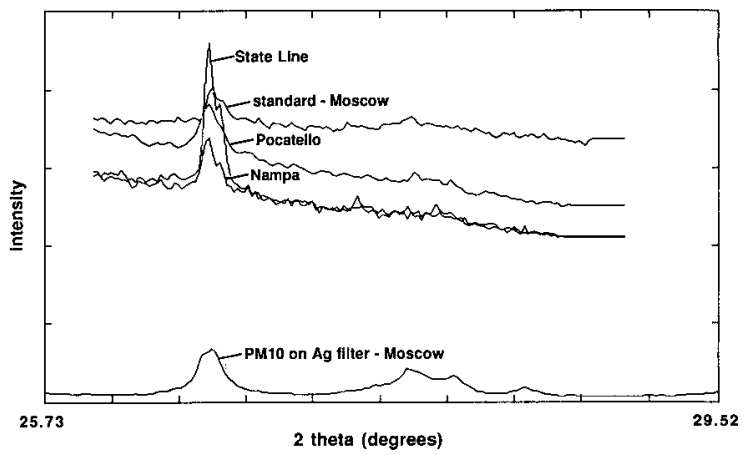

FIGURE 2. XRD patterns for four samples collected and X-rayed on glass-fiber filters and a portion of the 9/15/95 sample scanned on a silver membrane filter. Refer to Figure 1 for sample locations. 
Idaho, approximately 70 to 80 people die per year from emphysema, whereas approximately 350 to 400 people die per year Idaho from lung cancer.

\section{Database}

As large a database as possible was constructed to determine if high dust levels increase the chances of contracting lung cancer, bronchitis, asthma, and emphysema. The database included information on "dusty" occupations such as farming, mining, logging, and carpentry. The Idaho Department of Vital Statistics provided the data and assisted in constructing the database. Their search program provided a report of individuals who had died of the diseases 160-165 (Malignant Neoplasm of Respiratory and Intrathoracic Organs) and individuals who had died of the diseases 460-519 (Diseases of the Respiratory System) for the years 1969 to 1994 . These data also included the county, city, age, sex, occupational classification code, and industrial classification code, if available, for each individual. This database consisted of 24247 observations (i.e., deaths) over the past 25 years and is the foundation for the statistical analysis. The overall death rates from respiratory diseases for farmers and non-farmers were obtained from this database (Table 4). In general, farmers seem to have a slightly higher death rate for COPDs (491-493) and a slightly lower death rate for lung cancer than the general population. However, several other factors, such as smoking rates and age distribution, must be considered before any conclusions can be drawn from the data.

\section{SMRs}

Along with the disease rates that appear in Table 4, the standard mortality ratio (SMR) was also calculated. The SMR is a statistic that is routinely used to determine if death rates for certain populations are above or below the averages of other populations (Kahn and Sempos 1989). The standard mortality ratio $(\mathrm{SMR})$ is defined as:

$$
\mathrm{SMR}=\left[\frac{O}{E}\right] * 100
$$

where $O$ is the number of "observed deaths" in the population, and $E$ is the number of "expected deaths" in a reference population. SMRs over 100 indicate death rates higher than expected, and SMRs below 100 suggest that a population exhibits a lesser risk than does the reference population. To determine statistical significance, a standard error (SE) can be calculated for the SMR populations (Kahn and Sempos 1989). An approximate SE for the SMR can be found by:

$$
\mathrm{SE}(\mathrm{SMR}) \cong \frac{\mathrm{SMR}}{\sqrt{O}}
$$

where $\mathrm{SE}(\mathrm{SMR})$ is the standard error for the $\mathrm{SMR}$, and $O$ is the number of observations (i.e., deaths in the observed population). For example, in Table 4 the SMR for farmers' deaths from lung cancer is 88 with a standard error of 3 [written 88(3)], while for non-farmers the SMR value is $116(1)$. The smaller SE for non-farmers reflects the larger number of observed deaths from lung cancer for non-farmers than for farmers (7015 vs. 877). These SMRs indicate that farmers in Idaho have a lower than expected death rate from lung cancer when compared to the entire population of Idaho.

After calculating state rates and averages, a county examination was performed. The SMRs for lung cancer, combined COPDs (491, 492, and 493), and standard errors are summarized in Table 1. The COPDs were grouped to increase the number of observations and thus minimize the standard error. The Idaho SMRs were calculated using the United States as the reference population; thus, the U.S. death rates were used to estimate the number of "expected deaths." The county SMRs were calculated using Idaho death rates as the reference population.

\section{Smoking rates}

Other factors than dust contribute to respiratory disease. The predominant cause of respiratory disease is cigarette smoking. It is well documented that individuals who smoke increase their risk of dying from lung cancer by a factor of 10-15 (Hammond et al. 1978; Goldsmith 1994). Thus, it is important to know smoking rates in Idaho and attempt to factor these values into the data analysis. Data on smoking from 1983 to 1989 were obtained by the Idaho Department of Vital Statistics and used for the analysis of smoking rate by county (Table 1). The data were aggregated to calculate the desired rates. In cases where there were more than 50 respondents per county, a simple arithmetic mean was used. In addition, the standard error of the mean was included. For those counties in which there were less than 50 respondents, no standard errors were calculated; however, the standard errors are probably large because of small sample size. The statewide smoking rate is $20 \%$, which is below the national rate of $22 \%$ (BRFSS 1993).

\section{Adjusted SMRs}

SMR values can be refined by adjusting for known factors which may influence death rates, such as smoking and age.

\begin{tabular}{|c|c|c|c|c|c|c|c|c|}
\hline \multirow[t]{2}{*}{ Disease* $^{*}$} & \multicolumn{2}{|c|}{ Entire population } & \multicolumn{3}{|c|}{ Farmers } & \multicolumn{3}{|c|}{ Non-farmers } \\
\hline & Number & Rate \% & Number & Rate \% & SMR & Number & Rate\% & SMR \\
\hline $160-165 \& 460-519$ & 24247 & 13.3 & 3313 & 14.4 & $108(2)$ & 20934 & 13.1 & $99(1)$ \\
\hline 162 Lung Cancer & 7892 & 4.3 & 877 & 3.8 & $88(3)$ & 7015 & 4.4 & $116(1)$ \\
\hline 486 Pneumonia & 4292 & 2.4 & 600 & 2.6 & $111(5)$ & 3692 & 2.3 & $96(2)$ \\
\hline 491 Bronchitis & 384 & 0.2 & 68 & 0.3 & $150(18)$ & 316 & 0.2 & $100(6)$ \\
\hline 492 Emphysema & 2233 & 1.2 & 407 & 1.8 & $150(7)$ & 1826 & 1.2 & $100(2)$ \\
\hline 493 Asthma & 376 & 0.2 & 46 & 0.2 & $100(15)$ & 330 & 0.2 & $100(6)$ \\
\hline
\end{tabular}

TABLE 4. Rates of various diseases for farmers, non-farmers, and entire population

Notes: Total number of deaths in Idaho is 182,273 (1969-1994).

* Disease name and ICD9 code are given. 
Age is an important consideration for an epidemiological study because older populations will naturally have higher death rates, and higher SMRs, than younger populations. To adjust for this confounder, the age distribution for each county was calculated based on the 1980 Idaho census using five year intervals for the age distribution. The age distribution for the state of Idaho was also calculated. Using these data, each county's SMR was age-adjusted so that a particular county could be compared to other counties with the different ages factored in. The basic theory behind age correcting SMRs is to examine the population distributions for the study group and the comparison group and shift the study group's distribution to match that of the comparison group. Norton (1996) provides more details for the Idaho populations, and Kahn and Sempos (1989) provide details for the mathematical approach to these calculations.

Smoking is also a confounder when calculating lung cancer rates. Smoking adjustments were applied based upon the methods described in the National Longitudinal Mortality Study (NLMS) of 1988 (Roget 1988). Previous epidemiological studies have estimated the risk of death associated with cigarette smoking. These relative risks, combined with the rate of cigarette smoking for a group, can be used to adjust an SMR as a function of the proportion of the population that smokes. The expression for this SMR adjustment is:

SMR adjustment $=1-\frac{(\text { proportion smoking at specific level }) *(R R-1)+1}{(\text { proportion smoking in total }) *(R R-1)+1}$

where $R R$ is the relative risk for some activity. By using the rate of smoking for each county (Table 1), the rate of smoking in Idaho (20\%), the rate of smoking in the U.S. (22\%), and the relative risk (RR) for lung cancer, an adjustment for smoking can be applied to each county and the state as a whole. The relative risk for 25- to 64-year old white males was established at 5.09 in the 1988 NLMS study (Roget 1988).

Figure 3 illustrates how SMRs change after they have been adjusted. Figure $3 \mathrm{a}$ is a plot of smoking rates for all 44 counties in Idaho vs. nonadjusted lung cancer SMRs. As would be expected, a trend exists between lung cancer deaths and smoking rate. When the age adjustment is applied to the SMRs, the trend becomes less clear (Fig. 3b). Finally, after adding the smoking adjustment to the age-adjusted lung cancer SMRs, no trend exists, as desired. The non-adjusted and age-smoking adjusted SMRs for lung cancer are given in Table 1 along with their standard errors. The combined COPDs (Table 1) could only be age adjusted because no data were available to adjust the effect of smoking on these diseases (i.e., no $R R$ values were given in the NLMS study).

\section{Farmers vs. non-farmers}

One of the main goals of this study was to determine whether workers in dusty occupations, especially farming, have higher rates of respiratory diseases than those of the general population. Idaho is a dusty state with a large agriculture base, potatoes in the southern part of the state and wheat in the north. Current farming methods favor use of air-conditioned tractor and combine cabs, but these are fairly recent amenities. Our database spans from 1969 to 1994. A farmer who died in 1980 at the age of 70 would have begun farming in a cab-less tractor or combine and would have been exposed to large amounts of dust. As shown by our analysis, this dust was mostly inorganic in nature rather than organic combustion products composed mainly of hydrocarbons, as is more commonly found in large metropolitan areas.

Our original database from the Idaho Department of Vital Statistics contained occupation codes for each death which were used to separate deaths in the farming trades from the rest of the population (see Norton, 1996 for details). Table 4 lists all deaths from all respiratory diseases for both farmers and nonfarmers; death rates and SMRs could also be calculated from these data. The ICD classification 160-165 includes all malignant neoplasms of the respiratory system, of which 162 (cancer of the trachea, bronchus, and lung) is by far the most significant, accounting for $97 \%$ (ca.) of the cancers in 160-165 group. The ICD codes 460-519 include the non-malignant res-

\section{a. non-adjusted}

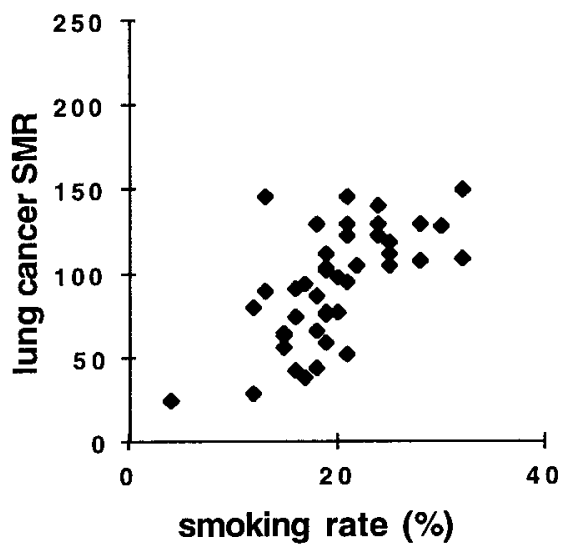

b. age-adjusted

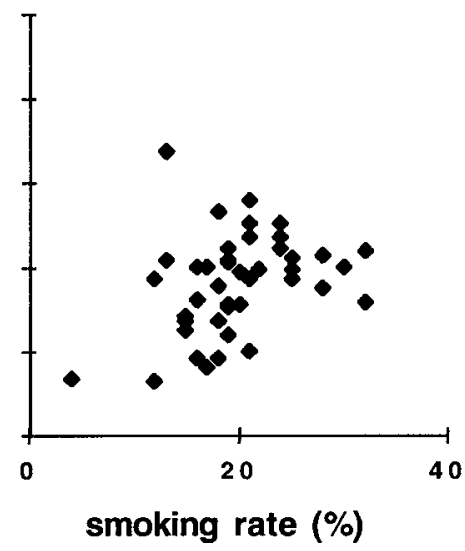

\section{c. age \& smoking adjusted}

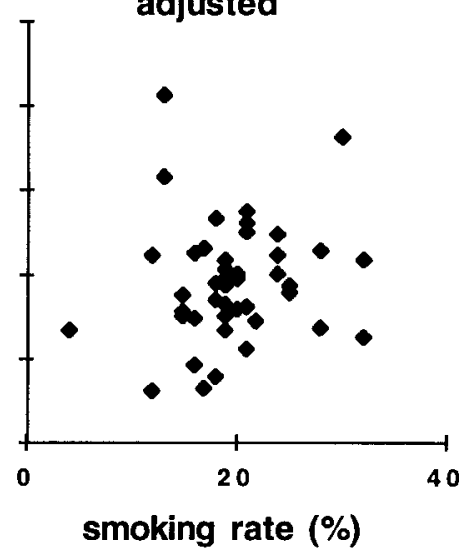

FIGURE 3. Non-adjusted (a) and adjusted (b and c) relationships between lung cancer SMRs and smoking rates for the 44 counties in Idaho. The non-adjusted (a) SMRs increase as smoking rate increases. In b the SMRs have been age-adjusted on a county-by-county basis, removing the effect of different age populations in the different counties. In $\mathbf{c}$ the age-adjusted SMRs from $\mathbf{b}$ are also smoking adjusted. 
piratory diseases such as COPDs (491-493) which account for $50 \%$ (ca.) of the deaths in this group. The other significant disease in this group is pneumonia (486), which comprises $30 \%$ (ca.) of deaths in the group. Several other rare diseases occur in this group, such as asbestosis (501) and silicosis (502), of which only 1 or 2 deaths occur each year. See WHO (1977) or Norton (1996) for more details on the ICD classification scheme.

The death rates in Table 4 are used to calculate SMRs for farmers and non-farmers. The Idaho state population is thus used to obtain the expected deaths (i.e., the denominator in Eq. 2). The farmers have slightly elevated SMR values, 108(1), as compared to the SMR for non-farmers, 99(1), when all the respiratory diseases are combined. The farmers also have elevated rates for pneumonia and the COPDs. However, the farmer lung cancer SMR, 88(3), is significantly below that of non-farmers, 116(1).

To apply age and smoking adjustments to these data would require information on the age distribution and smoking rates of farmers, which are not available. It could be speculated that farmers, in general, are older than the normal population because there is a general decrease in the number of people entering the field of farming due to increased mechanization of agricultural practices. If this is true, then the SMR would adjust to even lower values. Although there are no data on smoking rates for farmers as compared to the general population in Idaho, the NLMS study of Roget (1988) reports a smoking rate of $29 \%$ for agricultural workers as compared to $35 \%$ for all trades. Using these data and Equation 4, the farmer SMR would be adjusted upward from 88(1) to 98(1).

\section{TRENDS IN PM10 AND EPIDEMIOLOGICAL RESULTS}

High levels of PM10 have been related to various respiratory diseases, especially COPDs, and inhalation of quartz has been related to lung cancer (IARC 1997). Thus, given the data in the study, we attempted to find correlations between disease rates when comparing Idaho to the U.S. and comparing farmers to non-farmers. As shown above, Idaho and its farmers have lower rates for lung cancer than the rest of the U.S. but have higher rates for COPDs. We also obtained data on PM10 levels for specific counties and attempted to find trends in these data.

\section{PM10 and disease}

PM10 values were available for 14 of Idaho's 44 counties (Table 1). Figure 4a depicts the dependence of adjusted lung cancer SMRs on PM10. These data reveal no trend (i.e., increased levels of PM10 do not increase the rate of lung cancer). The dependence of adjusted COPD SMRs on PM10 is shown in Figure 4b. Again, no clear trend appears, though the data are more scattered.

Precipitation data for the past 30 years were obtained for each county from the State Climate Services at the University of Idaho (http://www.uidaho.edu/ climate). Figure 4c shows that, as expected, there is a general decrease in PM10 values with increased precipitation for the 14 counties in which PM10 data were available.

Recalling that higher PM10 values correlate to lower precipitation values (Fig. 4c), one might predict a trend for lower SMRs at higher precipitation values if high PM10 causes increases in lung cancer. This is not the case (Fig. 5a). In fact, SMRs increase slightly with precipitation. Figure $5 \mathrm{~b}$ is a plot of COPDs vs. precipitation and shows no clear trend relating SMRs to precipitation. Again, there might even be a slight increase in SMRs with increased precipitation.

\section{County analysis}

The western part of the northern panhandle of Idaho (i.e., Bonner, Kootenai, Benewah, Latah, and Nez Perce counties) and the southern Snake River Plain (i.e., from Canyon County east to Bonneville County) exhibit near desert conditions, while the center portion of the state (i.e., Idaho, Valley, Custer, and Lemhi counties) is very mountainous. These vast differences in climate and, in turn, dust levels, might lead to differences in respiratory disease rates. Figure 6a is a county-by-county map of the data given in Table 1 for unadjusted SMRs for lung cancer, and Figure $6 \mathrm{~b}$ contains the adjusted lung cancer SMRs. a.



b.

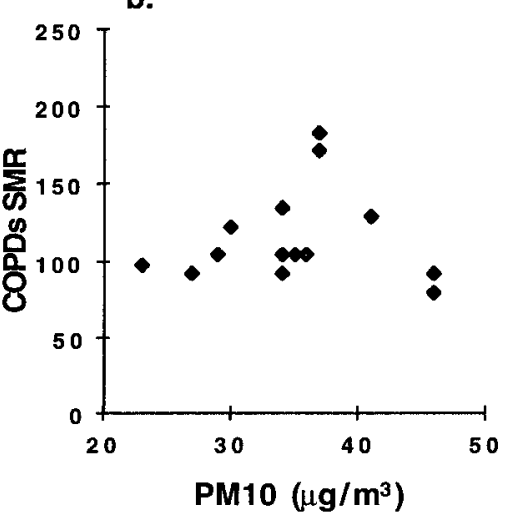

C.

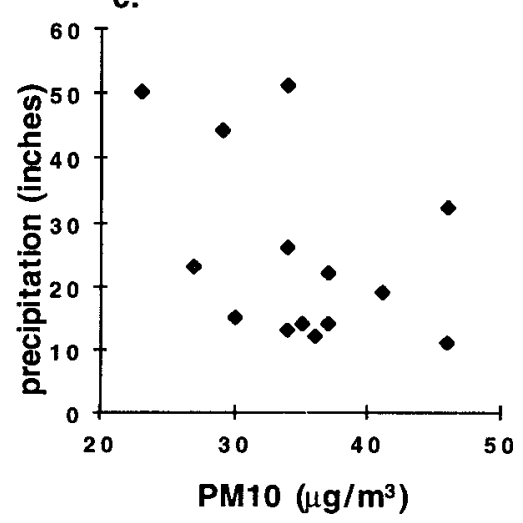

FIGURE 4. Plots of PM10 vs. adjusted (age and smoking) lung cancer SMR (a), adjusted (age) COPDs (b), and precipitation (c). PM10 data are only available for 14 of the 44 counties in the state, those with the higher populations (Table 1). There appears to be no trend between PM10 and lung cancer or COPD SMRs. 
a.

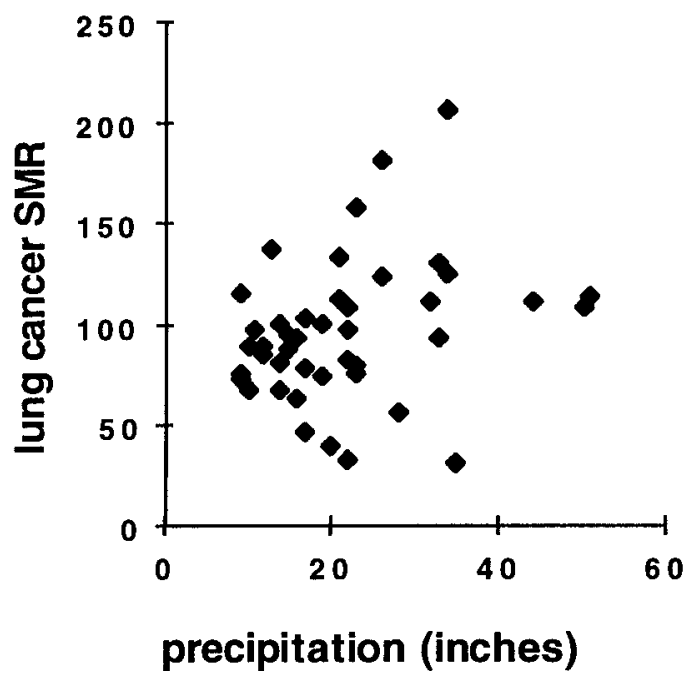

b.

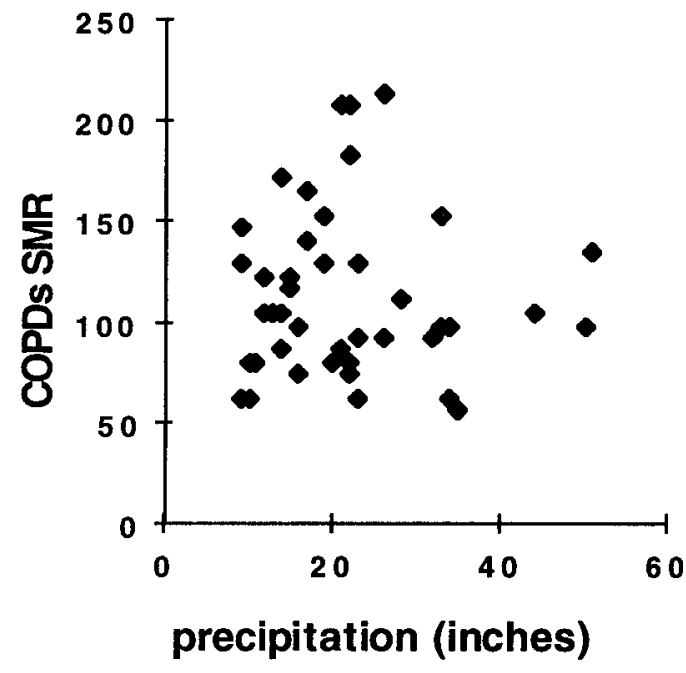

FIGURE 5. Plots of adjusted lung cancer SMRs (a) and adjusted COPDs (b) as a function of precipitation for 43 of Idaho's 44 counties. No trends are apparent in either case. However, SMRs for lung cancer plot around 100, indicating no increases in lung cancer, while the SMRs for COPDs tend to plot above 100, indicating a higher than expected rate for COPDs.

\section{a. non-adjusted lung cancer SMRs}

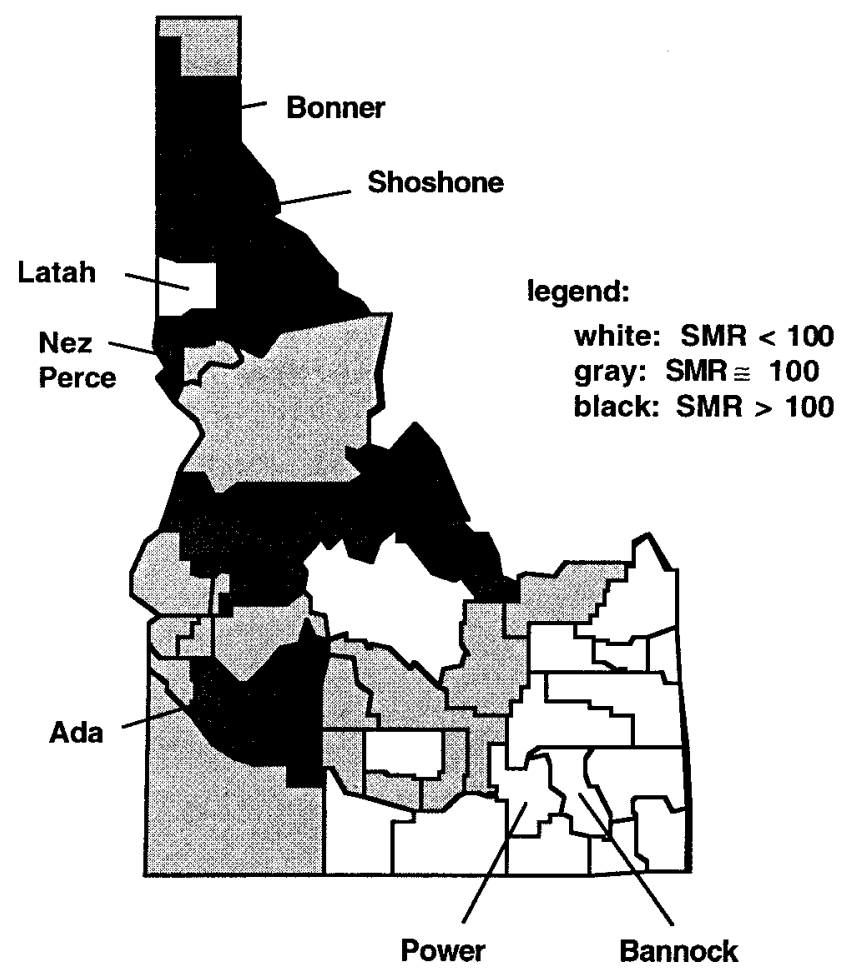

b. adjusted lung cancer SMRs

FIGURE 6. County breakdown of non-adjusted (a) and adjusted (b) lung cancer SMRs. Three types of shading exist on the maps: the darkest is used for counties that have an SMR significantly greater than 100, white is used for counties that have an SMR significantly below 100, and the lighter gray is used for counties that have an SMR statistically no different from 100. The significance is determined by adding or subtracting one SE(SMR), given in Table 1, to each SMR. If, for instance, after subtracting one SE from an SMR above 100, the SMR still is above 100, then it is considered significant. The five counties currently in non-attainment for PM10 are also labeled, along with Latah and Nez Perce counties. 
a. non-adjusted COPD SMRs



\section{b. adjusted COPD SMRS}

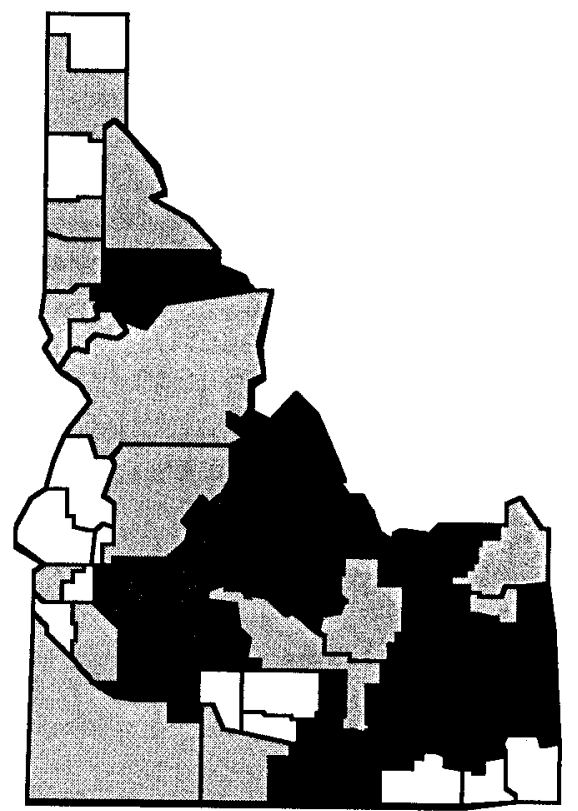

FIGURE 7. County breakdown of non-adjusted (a) and adjusted (b) COPDs SMRs. Counties in white have SMRs below 100, those in gray are approximately 100 , and those in black are above 100 . The five non-attainment counties are also shown.

Figure 7 shows the SMRs for COPDs. The importance of the SMR adjustment can be seen. Interestingly, an approximately inverse correlation exists between adjusted lung cancer SMRs (Fig. 6b) and adjusted COPDs SMRs (Fig. 7b). The southeastern portion of the state tends to have high COPD SMRs but low lung cancer SMRs, while the northern part of the state has low COPD SMRs but high lung cancer SMRs. These two dusty areas of the state exhibit opposite behaviors.

\section{Nonattainment counties}

Five counties in the state (Ada, Bannock, Bonner, Power, and Shoshone) fail to meet current EPA guidelines for PM10 (Figs. 6 and 7). The adjusted SMRs for lung cancer show that three of these counties have SMRs above 100 and the other two have SMRs statistically equal to 100 . The adjusted SMRs for COPDs are above 100 for two of these counties and statistically equal to 100 for the other three. It is worth noting that Ada and Bannock are fairly highly populated counties and, in general, COPD and lung cancer rates are shown to be higher in urban areas (EPA 1996).

\section{ACKNOWLEDGMENTS}

We thank Janet Wick and Chris Johnson at the Idaho Department of Vital Statistics for their help in collecting the mortality data, Matt Stoll at the Idaho Department of Environmental Quality for his help with regional PM10 data and for providing statewide filters for analysis, Dale Everson of the University of Idaho for his help in the epidemiology portion of this study, and Charlie Knowles of the University of Idaho for his help with the various analytical methods used in this study. Reviews by Peter Heaney, Cathy Skinner, and comments of the Associate Editor, Jill Banfield, are also greatly appreciated. We also thank the Idaho State Board of Education and the National Science Foundation (NSFDUE no. 9254158) for funding this investigation.

\section{REFERENCES CITED}

AIRS Executive Computer Software (1996) Version 3.0, Information Transfer Group, Research Triangle Park, North Carolina.

Agricola, G. (1556) De Re Metallica. Basel, Switzerland. Dover Publications, New York.

Behavioral Risk Factor Surveillance Survey (1993) Office of Health Promotion, Idaho Department of Health and Welfare, 1-29.

Checkoway, H., Heyner, N.J., Demers, P.A., and Breslow, N.E. (1993) Mortality among workers in the diatomaceous earth industry. British Journal of Industrial Medicine, 50, 586-597.

Dagel, G.E., Wehner, A.P., Clark, M.L., and Buschbro, R.L. (1986) Chronic inhalation exposure of rats to quartz. In D.F. Goldsmith, D.M. Winn, and C.M. Shy, Eds., Silica, Silicosis and Cancer: Controversy in Occupational Medicine, Chapter 25, p. 255-266. Praeger, New York.

Davis, L.K., Wegman, D.H., Monson, R.R., and Froines, J. (1983) Mortality experience of Vermont granite workers. American Journal of Industrial Medicine, 4, 705-723.

Dockery, D.W., Pope, C.A. III, Xu, X., Spengler, J.D. Ware, J.H., Fay, M.E., Ferris Jr., B.G, and Speizer, F.E. (1993) An association between air pollution and mortality in six U.S. cities. New England Journal of Medicine, 329, 1753-1759.

Feinleib, M. (1991) National Center for Health Statistics. Vital statistics of the United States, 1988, vol. II, mortality, part A. Public Health Service, Washington, D.C.

Frazier, T.M. and Sundin, D.S. (1986) Industrial demographics and populations at risk for silica exposures. In D.F. Goldsmith, D.M. Winn, and C.M. Shy, Eds., Silica, Silicosis and Cancer: Controversy in Occupational Medicine, p. 3-9. Praeger, New York.

Goldsmith, D.F. (1994) Health effects of silica dust exposure. In Mineralogical Society of America Reviews in Mineralogy, 29, 546-606.

Hammond, C.E., Garfinkel, L., and Lew, A.L. (1978) Longevity, selective mortality, and competitive risks in relation to chemical carcinogenesis. Environmental Research, 16, 153-173. 
Heaney, P.J., Prewitt, C.T., and Gibbs, G.V. (1994) Silica. Mineralogical Society of America Reviews in Mineralogy, 29, 606 p.

Hnizdo, E. and Sluis-Cremer, G.K. (1991) Silica exposure, silicosis, and lung cancer: A mortality study of South African gold miners. British Journal of Industrial Medicine, 49, 472-479.

IARC (1987a) IARC Monographs on the Evaluation of the Carcinogenic Risk of Chemicals to Humans, Silica and Some Silicates, v. 42, World Health Organization, International Agency for Research on Cancer, Lyon, $288 \mathrm{p}$.

IARC (1987b) IARC Monographs on the Evaluation of the Carcinogenic Risk of Chemicals to Humans, Overall Evaluations of Carcinogenicity: An Updating of IARC Monographs 1 to 42, Supplement 7, World Health Organization, International Agency for Research on Cancer, Lyon, $440 \mathrm{p}$.

IARC (1997) IARC Monographs on the Evaluation of the Carcinogenic Risk of Chemicals to Humans, Silica, Some Silicates, Coal Dust, and Para-aramid Fibrils, v. 68, World Health Organization, International Agency for Research on Cancer, Lyon, $506 \mathrm{p}$.

Kahn, H.A. and Sempos, C.T. (1989) Statistical Methods in Epidemiology. Oxford University Press, New York, 85-137.

Klein, C. (1993) Rocks, Minerals, and a Dusty World. In Mineralogical Society of America Reviews in Mineralogy, 28, 7-59.

National Institute for Occupational Safety and Health (1994) In Peter M. Eller, Ed., NIOSH Manual of Analytical Methods (NMAM), Fourth Edition. Cincinnati, Ohio.

Norton, M.R. (1996) Health effects of crystalline silica in Idaho. Master of Science Thesis, University of Idaho, $119 \mathrm{p}$.

Paracelsus, T. (1567) Von der Bergsucht. Sebaldum Mayer, Dilingen, Germany.

Roget, E. (1988) A mortality study of one million persons by demographic, social, and economic factors: 1979-1981 follow-up: U.S. National Longitudinal Mortality Study. U.S. Department of Health and Human Services, Public Health Service, National Institutes of Health, 1-307.

Ross, M., Nolan, R.P., Langer, A.M., and Cooper, W.C. (1993) Health effects of minerals dusts other than asbestos. In Mineralogical Society of America Reviews in Mineralogy, 28, 361-407.

Russel, A.E. (1941) The health of workers in dusty trades: restudy of a group of granite workers. U.S. Public Health Service Bulletin 269, Washington, D.C.

Saffiotti, U., Daniel, L.N., Mao, Y., Williams, A.O., Kaighn, M.E., Ahmed, N., and Knapton, A.D. (1993) Biological studies on the carcinogenic mechanisms of quartz.
In Mineralogical Society of America Reviews in Mineralogy, 28, 523-544.

Schwartz, J. (1994) Total suspended particulate matter and daily mortality in Cincinnati, Ohio. Environmental Health Perspective, 102, 186-189.

Schwartz, J. (1995) Short term fluctions in air pollution and hospital admissions of the elderly for respiratory disease. Thorax, 50, 531-538.

Schwartz, J. (1996) Air pollution and hospital admissions for respiratory disease. Epidemiology, 7, 20-28.

Skinner, H.C.W., Ross, M., and Frondel, C. (1988) Asbestos and Other Fibrous Materials, 204 p. Oxford University Press, New York.

Spietoff, A., Wesch, H., Wegener, K., and Klimisch, H. (1992) The effects of Thoratrast and quartz on the induction of lung tumors in rats. Health Physics, $63,101-110$.

Snyder, R.L., and Bish, D.L. (1989) Quantitative Analysis. In Mineralogical Society of America Reviews in Mineralogy, 20, 101-144.

U.S. Environmental Protection Agency (1986) Review of the national ambient air quality standards for particulate matter: updated assessment of scientific and technical information, addendum to the 1982 OAQPS staff paper. Research Triangle park, North Carolina, Office of Air Quality Planning and Standards, Strategies and Air Standards Division; report number EPA/450/05-86/012.

U.S. Environmental Protection Agency (1995) Ambient levels and noncancer health effects of inhaled crystalline and amorphous silica. Research Triangle Park, North Carolina, National Center for Environmental Assessment. Office of Research and Development. EPA report number EPA 600/R-95/115.

U.S. Environmental Protection Agency (1996) Review of the national ambient air quality standards for particulate matter: Policy assessment of scientific and technical information. OAQPS Staff Paper, Research Triangle Park, North Carolina, Office of Air Quality Planning and Standards. EPA report number EPA 452/R-96-013.

Wagner, M.M.F., Wagner, J.C., Davies, R., and Griffiths, D.M. (1980) Silica-induced malignant histiocytic lymphoma: incidence linked with strain of rat and type of silica. British Journal of Cancer, 41, 908-917.

World Health Organization (1977) International Classification of Diseases, $259 \mathrm{p}$. World Health Organization, Geneva.

MANUSCRIPT RECEIVED FebruARY 16, 1998

MANUSCRIPT ACCEPTED MARCH 29, 1999

PAPER HANDLED BY JILLIAN BANFIELD 